\title{
Determinants of Safety Measure Implementation System in Building Construction Companies in Lagos, Nigeria
}

\author{
Esther Uzoamaka Nzomiwu, Charles Uwadiae Oyegun , Nnadede Kasarachi
}

\begin{abstract}
Construction is a complex activity where various stake-holders are present working under constant challenge by demands of the job. Each job has several of its safety and risk factors, requiring quality and safety management systems to be established. The purpose of this study was to determine the elements of safety management system that predict the level of safety measure implementation in building construction companies in Lagos State, Nigeria. The data utilized in this study were based on a proportionate stratified sampling of construction workers representing the selected companies for this study. Out of the 285 self-administered questionnaires distributed, 262 were used for the study, representing a response rate of $91.96 \%$. Data were analyzed by using descriptive and inferential statistics and presented in tables and figures. Findings from the study showed that three elements of safety management system significantly predicted level of safety measure implementation in the construction companies under study. These include; management leadership (x1) with a beta

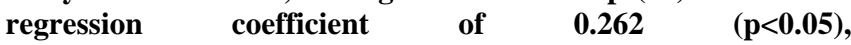
identification/assessment of hazard $(x 3)$ with a beta regression coefficient of $0.140(p<0.05)$ and safety communication $(x 7)$ with a beta regression coefficient of $0.308(p<0.05)$. These three elements therefore serve as major determinants of effective safety management system implementation of the construction companies under study.
\end{abstract}

Index Terms - Safety management system, Safety measure implementation, Construction.

\section{INTRODUCTION}

Globally, the importance of the construction industry to national economies can never be over emphasized. According to [1], by 2020 construction will account for $13.2 \%$ of world GDP indicating an upward trend. This is seen in the provision of basic infrastructure such as road networks, commercial and residential buildings and facilities to the other sectors of economies. Furthermore, construction's sizeable amount of economic growth is through backward and forward linkages since construction activities utilize goods and services from other industries. Employment creation by construction activities is another important aspect in economic development.

Despite the documented positive gains brought by the construction industry, there are negative attributes which are associated with construction work. Construction work is

Esther Uzoamak Nzomiwu, Centre for Occupational Health Safety and Environment, University of Port Harcourt, Port Harcourt, Nigeria

Charles Uwadiae Oyegun, Centre for Occupational Health Safety and Environment, University of Port Harcourt, Port Harcourt, Nigeria

Kasarachi Nnadede, Centre for Occupational Health Safety and Environment, University of Port Harcourt, Port Harcourt, Nigeria dangerous, the International Labour Organization (ILO) estimates at least 60,000 fatal accidents a year on construction sites around the world that is one in six of all fatal work-related accidents [2]. The global trade union federation puts the figure much higher at 108,000 with construction responsible for $30 \%$ of all work-related accidents. In Nigeria, the construction industry looses at least $5 \%$ of its workforce annually to injuries and fatalities, while the influx of new blood has reduced by $17 \%$ compared to that of 1970s [3]. Construction is a complex activity where various stake-holders are present working under constant challenge by demands of the job. Each job will have several of its safety and risk factors, requiring quality and safety management systems to be established as indicated by [4]. Several risk factors including organizational structure, communication, clear instructions, safety culture, codes and standards, training, leadership and responsibility have been suggested to have influence on the general safety at the workplace. The objective of this study is to determine the most influential elements of safety management system that are predictors of a safety measure implementation system as perceived by the workers. This may assist management in optimizing the utilization of available resources.

Different reputable organizations and agencies have over the years advanced various description for Safety management System. Safety management system (SMS) is an organized system of strategies employed in a working environment to reduce accident occurrence or illness. An effective safety management system comprises of; involvement/commitment of management, identification/assessment of hazards, controlling of hazards, training, emergency response, reporting and investigation of incidents as well as communication. Given that there is no comprehensive and complete information based on actual recorded data on the determinants of safety measure implementation systems in the building construction industry in Nigeria, the purpose of this study was to identify the information gap on determinants of safety measure implementation systems in the building construction industry in Lagos State.

\section{RESEARCH METHODOLOGY}

\section{A. Research Design}

The study uses a cross-sectional design, where data are gathered from a large sample at specific times with aim of describing them without manipulation of variables [5]. In the study, the researcher looked at collecting data from sample workers from various building construction companies in Lagos state to describe the relationship between elements of safety management system and effective implementation of 
safety measures in the building construction companies in the study area. To achieve this, survey method was used for data collection via questionnaires. The survey research method provides a means of accessing information on population at a point in time.

\section{B. Study Area}

The study area is Lagos State, situated in the South-West zone of Nigeria. It is between latitudes $6^{\circ} 23^{\prime} \mathrm{N}$ and $6^{\circ} 41^{\prime} \mathrm{N}$ and between longitudes $2^{\circ} 42^{\prime} \mathrm{E}$ and $3^{\circ} 42^{\prime} \mathrm{E}$. On its North and East boundary is Ogun State. On the West, is the Republic of Benin, and on its south is the Atlantic Ocean/Gulf of Guinea. The State encompasses an area of 358,861 hectares or $3,577 \mathrm{sq} . \mathrm{km}$. Lagos State plays host to quite a number of building construction companies, both big and small among which are Julius Berger Nigeria Limited, Reynolds Construction Company (RCC), Energo Building Construction Company Limited. Consequently, Lagos was considered a suitable area for the study and others. Lagos state is a hub of industrial and commercial activities. Hence, construction activities are constantly ongoing for expansion and development of business activities. Consequently, the state was considered suitable for the study.

\section{Study Population}

The target population for the study comprised of safety personnel, project managers and directors, site engineers and foremen from major building construction companies that operate in Lagos State. These companies include: Adold Engineering Company Limited, Julius Berger Nigeria Limited, Reynolds Construction Company (RCC), Energo Building Construction Company Limited, China Civil Engineering Construction Company (CCECC), Cappa and D'alberto Plc, El-alan Construction Company (Nigeria) Ltd, Constain West Africa, I.T.B. Construction Limited, Buildstruct Advance Builder Company, Brunelli Construction Company (Nigeria) Limited and Oat Construction Nigeria Limited.

\section{Inclusion and Exclusion Criteria}

These target companies as at the study period were construction companies that deal in building of roads, houses and bridges. Companies included were those ones actively engaged in projects at the time of the study. They were also companies that had at least 37 workers including safety personnel as well as professionals and practitioners in the building industry on site at the time of the study. These people were included because the researcher thought they would understand the safety needs and requirements in the building construction activities. On the other hand, companies with less than 37 onsite construction workers and did not have safety personnel as well as building professionals and practitioners were excluded from the population frame of the study.

\section{E. Data Collection and Quality Control}

Questionnaire was utilized for the data collection designed to measure independent and dependent variables. The independent variable comprised the core elements of safety and health practice recommended for construction activities by Occupational, Safety and Health Academy [6]. These include leadership by management, employee participation, identification and assessment of hazards, hazard prevention and control, education and trainings, evaluation and improvement of programme, communication and coordination. The dependent variable comprised the implementation of safety measures.

The questionnaire was subjected to face validity before the supervisors of this research and its reliability coefficient was obtained through test and retest method. The reliability coefficient was determined by distributing 20 copies to 20 top personnel of building construction companies who are not part of the study twice at an interval of two weeks. Data obtained were then subjected to Pearson Product Moment Correlation formula to calculate the reliability. A reliability coefficient of 0.95 was obtained.

\section{F. Data Analysis}

Descriptive and inferential statistics were employed for the data analysis. Descriptive statistics employed include majorly frequencies and percentages, used for interpreting the demographic data collected. Analysis of Variance (ANOVA) was also employed in this study. Data gathered for the fourth objective were subjected to regression analysis. Multiple regression analysis was employed to get the model that predicts implementation of safety measure from the elements of safety and health targets. Results are presented in Figures and Tables.

\section{RESULTS AND DISCUSSION}

\section{A. Demographic Characteristics}

Figure 1 shows the percentage $(\%)$ distribution of respondents by their gender. It has been observed overtime, that there are some jobs prescriptions that are most suitable for males to handle safely than females or expectant mothers, for instance, lifting of heavy items. Figure 1 displays that 221 of the respondents were male while 41 were female. This shows that $84.35 \%$ of the populace was male and $15.65 \%$ were female. Data from the Figure shows that 76 respondents had age ranging from 18 - 35 years which constituted $29.01 \%$ of the entire number of 262 respondents. Further, 142 constituting $54.20 \%$ respondents had age ranging from 36 55 years while 44 respondents constituting $16.79 \%$ were of age 56 years - above. This statistic shows that construction companies in the study area had more workers of in the age-bracket; 35 - 55 than others.

Data from Figure 1 shows 161 married workers and 101 single workers. This depicts that married workers constituted $61.45 \%$ of the sample while single workers constituted $38.55 \%$. This statistic indicates that construction companies in the viewed area had more of married workers than single workers. The Figure also shows that 9 respondents were holders of WAEC/Equivalents which constituted $7.25 \%$ of the number of 262 respondents. Further, 176 constituting $67.18 \%$ respondents were Bachelor's degree holders or its equivalents while 67 constituting $25.57 \%$ respondents were degree holders higher than Bachelor's degree. 

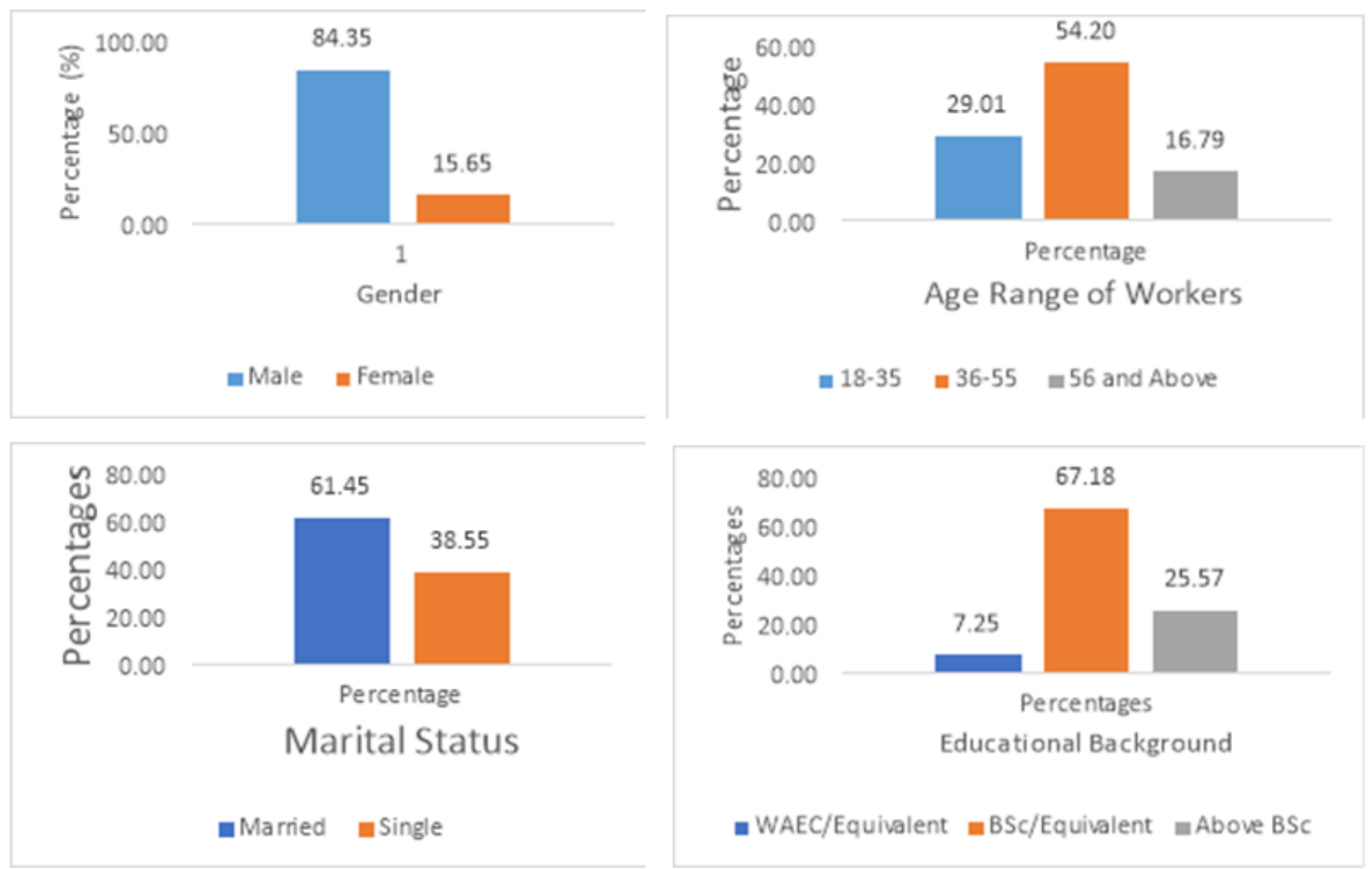

Figure 1: Demographic Characteristics of Respondents

-WAEC/Equivalent $\mathrm{BSC} /$ Equivalent $\mathrm{B}$ Above BSC

\section{B. Predictors of Safety Measure Implementation System}

Table 3 shows the standardized coefficients for $x_{1}$ to $x_{7}$ in the regression model. Management leadership $\left(\mathrm{x}_{1}\right)$ has a coefficient of $0.262(p<0.05)$. Identification/Assessment of Hazards $\left(\mathrm{x}_{3}\right)$ has a coefficient of $0.140(p<0.05)$. Safety Communication $\left(\mathrm{x}_{7}\right)$ has a coefficient of $0.308(p<0.05)$. This is an indication that Management leadership, Identification/Assessment of hazards and Safety communication significantly predict safety measure implementation in the study area. These variables that significantly predict safety measure implementation were fit into the model while other variables that did not significantly predict safety measure implementation were removed from the initial model. Substituting these coefficients, the final model becomes:

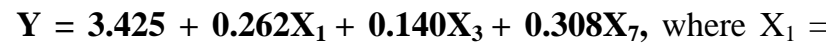
management leadership; $\mathrm{X}_{3}=$ identification and assessment of hazards; $\mathrm{X}_{7}=$ safety communication.

From Table 2, showing the analysis of variance, $F(7,254)$ $=36.08, p<0.05$. This indicates that the regression model significantly predicts implementation of safety measures in the construction companies in the study area. However, this further shows that management leadership, identification/assessment of hazards and communication were found to be the variables causing this significant prediction found from the ANOVA table. From Table 1, a coefficient of determination $\left(\mathrm{R}^{2}\right)$ of 0.4986 shows that $49.86 \%$ of the variation in the safety measure implementation level were explained by the independent variables. The intercept of the regression-model (3.425) shows that regardless of management leadership, identification/assessment of hazards, and safety communication, level of implementation of safety measures will be 3.425 .

The coefficient of management leadership $\left(\mathrm{X}_{1}\right)$ is 0.262 . This depicts that for every unit increase in management leadership, safety measure implementation level will increase by 0.262 unit if other independent variables are kept constant. The coefficient of identification/assessment of hazards $\left(\mathrm{X}_{3}\right)$ is 0.140. This implies that for every unit increase in identification/assessment of hazards, level of implementation of safety measures will increase by 0.140 unit if other independent variables are kept constant. The coefficient for safety communication $\left(\mathrm{X}_{7}\right)$ is 0.308 . This denotes that for every unit improvement in safety communication, level of implementation of safety measures will increase by 0.308 unit if other independent variables are kept constant.

To test for contribution of each of the independent variables to the prediction of dependent variable, test of multicollinearity among independent variables was first conducted. This was achieved using variance of inflation factor (VIF) in SPSS (Table 3). From this result, the significant test for each independent variable was checked. In Table 3, three (3) of the independent variables produced significant result. They include management leadership $(t=4.245, \quad p=0.000)$, identification/assessment of hazards $(t=2.543, p=0.012)$ and safety communication $(t=5.396$, $p=0.000)$. This depicts that management leadership, identification/assessment of hazards and safety communication predict level of implementation of safety measure significantly. Meanwhile, there was no statistically significant linear dependence of safety measure implementation level on employee participation $(t=1.014$, $p=0.311)$, prevention/control of hazards $(t=1.286, p=0.200)$, safety training $(t=0.143, p=0.886)$ and evaluation/control detected $(t=-0.433, p=0.666)$. 
Table 1: Summary Table for Regression Model

\begin{tabular}{lc}
\hline & Regression Statistics \\
\hline Multiple R & 0.706111 \\
R Square & 0.498592 \\
Adjusted R Square & 0.484774 \\
Standard Error & 3.066314 \\
Observations & 262 \\
\hline
\end{tabular}

Table 2: ANOVA for Regression Model

\begin{tabular}{llllll}
\hline Sources of Variation & $d \boldsymbol{f}$ & $\boldsymbol{S S}$ & $\boldsymbol{M S}$ & $\boldsymbol{F}$ & $\boldsymbol{P}$-value \\
\hline Regression & 7 & 2374.77 & 339.25 & 36.08 & 0.000 \\
Residual & 254 & 2388.18 & 9.402 & & \\
Total & 261 & 4762.95 & & & \\
\hline
\end{tabular}

Table 3: Intercept and Coefficients

\begin{tabular}{lccccccc} 
& $\begin{array}{c}\text { Unstandardized } \\
\text { Coefficients }\end{array}$ & $\begin{array}{c}\text { Standardized } \\
\text { Coefficients }\end{array}$ & & \multicolumn{3}{c}{ Collinearity Statistics } \\
& $\mathbf{B}$ & $\begin{array}{c}\text { Std. } \\
\text { Error }\end{array}$ & Beta & $\mathbf{t}$ & Sig. & Tolerance & VIF \\
\hline (Constant) & 3.425 & 1.679 & & 2.040 & .042 & & \\
Mgt Leadership & .229 & .054 & .262 & 4.245 & .000 & .519 & 1.927 \\
Employee Participation & .065 & .064 & .074 & 1.014 & .311 & .368 & 2.719 \\
Hazard Identification & .154 & .060 & .140 & 2.543 & .012 & .652 & 1.533 \\
Hazard Prevention & .072 & .056 & .089 & 1.286 & .200 & .408 & 2.451 \\
Safety Training & .010 & .067 & .011 & .143 & .886 & .325 & 3.077 \\
Safety Programme & .024 & .055 & .031 & .433 & .666 & .379 & 2.641 \\
Evaluation & & & & & & & \\
Safety Communication & .330 & .061 & .308 & 5.396 & .000 & .607 & 1.649
\end{tabular}

The result of regression analysis showed that although, the elements of safety management system including management leadership, employee participation, hazard identification, hazard prevention, safety training, safety evaluation and safety communication all contributed to the safety measure implementation in the studied companies, however, management leadership, hazard identification and safety communication predicted safety measure implementation significantly at 0.05 level of significance in the study area. The test of the hypothesis further shows that management leadership, employee participation, identification/assessment of hazards, prevention/control of hazards, training, evaluation/improvement and communication significantly predict level of safety measure implementation in construction companies under study. The result indicates that $53.70 \%$ variation in safety measure implementation level was elucidated by the independent variables. The result also showed that management leadership, identification/assessment of hazards and safety communication predict level of safety measure implementation significantly. Meanwhile, there existed nil statistically significant linear dependence of level of safety measure implementation on employee participation, prevention/control of hazards, safety training and evaluation/improvement detected.

This finding agrees with that of [7] who stipulated that safety communication influences safety measure implementation. The findings moreso, corroborate that of [8] from a literature review, that; factors which affect safety compliance include among others, safety communication, management commitment, safety training, safety risk assessment among other factors. This result aligns with the 
result of [9] who conducted a study to find out factors that determine safety performance among construction workers in construction companies in Northern Cyprus. The study found that safety training, health/safety knowledge of construction workers as well as safety planning and safety assessment significantly contribute to health and safety of workers in the construction sites. The result also agrees with the result of [10] who conducted a study to identify and analyse factors that influence safety implementation in construction companies in Saudi Arabia. The study found that management support, clear and reasonable safety objectives, personal attitude, teamwork among workers, effective safety measure enforcement by management, safety training and safety supervision were critical factors that impact greatly on safety implementation in the construction companies studied. Furthermore, the result agrees with the result by [11] who carried out a study to investigate the factors influencing safety management performance in building construction companies in Ghana. The result revealed that limited safety communication, poor personal safety protection and awareness among workers, nonchalant attitude to safety, and inadequate safety laws and enforcement negatively impact safety performance in the construction sites studied. The result also agrees with result of the studies by [12][13] who found that training of staff, engagement of safety officers on sites and adherence to safety rules and regulations, commitment of top-level personnel in construction companies, provision of personal protective equipment, communication between management and workers as well as safety supervision influence use of safety wears and safety performance by workers.

\section{CONCLUSION}

The study shows that three elements of safety management system were found to significantly predict level of safety measure implementation in the construction companies under study. These included management leadership, hazards identification/assessment and safety communication. These three elements therefore serve as major determinants of effective safety management system implementation of construction companies under study.

\section{DECLARATION OF INTEREST}

The author(s) declare no potential conflict of interest with respect to the research, authorship, and/or publication of this article.

\section{ACKNOWLEDGEMENT}

The authors did not receive funding for the project from anybody.

\section{REFERENCES}

[1] Kirombo, H. M. (2012). Factors affecting implementation of occupational health and safety measures in the construction industry: the case of Mombasa County, Kenya (Doctoral dissertation, University of Nairobi, Kenya).

[2] Lingard, H. (2013). Occupational health and safety in the construction industry. Construction management and economics, 31(6), 505-514.
[3] Oh, J. I. H., \& Sol, V. M. (2008). The policy program improving occupational safety in the Netherlands: An innovative view on occupational safety. Safety science, 46(2), 155-163.

[4] Mehta, R. K., \& Agnew, M. J. (2010). Analysis of individual and occupational risk factors on task performance and biomechanical demands for a simulated drilling task. International Journal of Industrial Ergonomics, 40(5), 584-591.

[5] Thomas, L. (2020). What is a cross-sectional study? Retrieved June, 21, 2020 from https://www.scribbr.com/methodology/cross-sectional-study/

[6] Occupational Safety and Health Administration (2016) Recommended practices for safety \& health programs in construction. Retrieved from https://www.osha.gov/shpguidelines/ docs/8524_OSHA_Construction_Guidelines_R4.pdf

[7] Wamuziri, S. (2013). Factors that influence safety culture in construction. Proceedings of the Institution of Civil Engineers-Management, Procurement and Law, 166(5), 219-231.

[8] Zin, S. M., \& Ismail, F. (2012). Employers' behavioural safety compliance factors toward occupational, safety and health improvement in the construction industry. Procedia-Social and Behavioral Sciences, 36, 742-751.

[9] Idoga, E.P. (2018). Analysis of Factors Affecting the Health and Safety of Construction Workers. Paper presented at the 5th International Project and Construction Management Conference of the Faculty of Engineering, Civil Engineering Department, Faculty of Engineering, Cyprus International University, North Cyprus.

[10] Al Haadir, S., \& Panuwatwanich, K. (2011). Critical success factors for safety program implementation among construction companies in Saudi Arabia. Procedia engineering, 14, 148-155.

[11] Agyekum, K., Simons, B., \& Botchway, S.Y. (2018). Factors influencing the performance of safety programmes in the Ghanaian construction industry. Acta Structilia, 25(2), 39-68.

[12] Ogundipe, K.E., Owolabi, J.D., Olanipekun, E.A., Olaniran, H.F., Akuete, E., \& Fagbenle, A. O. (2018). Factors affecting effective use of safety wears among construction site operatives: lessons from indigenous firms in South Western Nigeria. International Journal of Applied Engineering Research, 13(6), 4314-4325.

[13] Nawi, M. N. M., Ibrahim, S. H., Affandi, R., Rosli, N. A., \& Basri, F. M. (2016). Factor affecting safety performance construction industry. International Review of Management and Marketing, 6(S8), 280-285. 